Original Research Article

\title{
Assessment of medical students' attitude towards didactic lectures taken in pharmacology in a private medical college
}

\author{
Umamaheswari A.*, Umamageswari M. S., Sathiya Vinotha A. T.
}

Department of Pharmacology, Karpagam Faculty of Medical Sciences, Coimbatore, India

Received: 30 March 2017

Accepted: 11 May 2017

\section{*Correspondence to:}

Dr. Umamaheswari A., Email: dr.uma.pharmac@ gmail.com

Copyright: (C) the author(s), publisher and licensee Medip Academy. This is an openaccess article distributed under the terms of the Creative Commons Attribution NonCommercial License, which permits unrestricted noncommercial use, distribution, and reproduction in any medium, provided the original work is properly cited.

\begin{abstract}
Background: To assess the attitude of second year medical students towards the teaching Principles in Pharmacology didactic lecture classes.

Methods: It was a descriptive epidemiological and questionnaire based study. Second year students who were attending pharmacology lecture classes for a period of one month (nearly 8 lectures) were given questionnaire and ask to fill it by assessing the theory classes which was conducted throughout that month. Each question was graded with mark and finally total score was converted to 50 marks. Five-level Likert's criteria were used to analyze few questions in the questionnaire. Data were analyzed by frequency distribution.

Results: Out of 115 students who attended the questionnaire session, $61 \%$ students were having a very good and better attitude towards the faculty talking Pharmacology lecture classes and remaining students have a few lacking areas in the teaching mode which should be analyzed.

Conclusions: Students have good attitude towards the faculty taking didactic lectures and the lacking areas can be future improved by efficient planning of interactive and interesting lecture methods for the usefulness of students as well as the teacher.
\end{abstract}

Keywords: Attitude, Second year medical students, Pharmacology lectures

\section{INTRODUCTION}

Pharmacology is the study of drugs. In pharmacology teaching will be a combination of lectures and practical sessions. ${ }^{1,2}$ Lecture is a traditional and didactic method of teaching. It is the most common method of teaching which is used to provide knowledge and information to a vast number of medical students but there is negligible student involvement in these types of teaching process. ${ }^{3}$ Medical teachers are working hard to implement diverse teaching techniques to educate medical students who were formerly thought only by blackboard and slide projectors. Now day's audio visual aids such as power point have been used as one of the newer methods. The optimum use of audio visual aids is essential for their learning. Traditional didactic lecture is an inactive method in nature and less effective as compared with active learning methods, such as problem-based learning.
However, a well-efficient lecture remains one of the most powerful ways to integrate and provide information from numerous sources on scientific topics. ${ }^{4,5}$ Hence this study aims to analyze student's attitude towards the medical education teaching skills and methods.

Aim of the study was to evaluate the attitude of second year medical students towards the teaching principles in Pharmacology didactic lectures.

\section{Objectives}

- To evaluate students' perception regarding the motivation, teaching, communication and linguistic aspects of the faculty during the lecture classes.

- To evaluate the effectiveness of teaching with regard to content and teaching methods. 
- To analyze students' level of satisfaction about the faculty with respect to teaching, insisting on newer concepts, including research ideas.

- To know whether introduction, objectives, summary, take home message of a particular topic are covered by the faculty during the lectures.

\section{METHODS}

Pharmacology topics by pharmacology teachers to $2^{\text {nd }}$ year MBBS students for a period of one month in 8 lecture classes.

\section{Inclusion criteria}

- Second MBBS students who give consent to participate in my research study

- $\quad$ Second MBBS students who are present during the questionnaire study

\section{Exclusion criteria}

- $\quad$ Second MBBS students who are not giving consent to participate in the study

- $\quad$ Second year MBBS students those who are absent during the questionnaire Study

- $\quad$ All other MBBS students in the college excluding second year MBBS students

- $\quad$ Partially filled or unfilled questionnaire even after giving consent

Type of study was descriptive epidemiological study.

Duration of the study was one month from $1^{\text {st }}$ July 2015 to $31^{\text {st }}$ July 2015.

\section{Study tool}

\section{Feedback assessment form}

Study was carried out at Department of Pharmacology, Private Medical College, Coimbatore.

A total of 145 students studying second year MBBS from a private medical college was included in the study. Informed consent was obtained and the study was conducted by providing a planned questionnaire for assessing the attitude of medical students towards professional teaching skills and methods. An assessment was set with a maximum of 50 marks to evaluate the students' attitude towards facilitator and the presentation. Each question was graded with mark and finally total score was converted to 50 marks and no negative marks were awarded to questions unanswered. Five-level Likert's criteria were used to analyze few questions in the questionnaire. ${ }^{6}$ Based on the marks obtained, the attitude of students towards faculty was classified into 6 categories. Later the data were analyzed followed by tabulation of results and interpretation was done.

\section{Statistical analysis}

Data were analyzed statistically using frequency distribution

\section{RESULTS}

$96 \%$ of students said that faculties give introduction to the lectures in an interesting manner, $92 \%$ said that they were satisfied with the teaching methods and $91 \%$ said that the objectives of the classes were fully achieved (Figure 1).

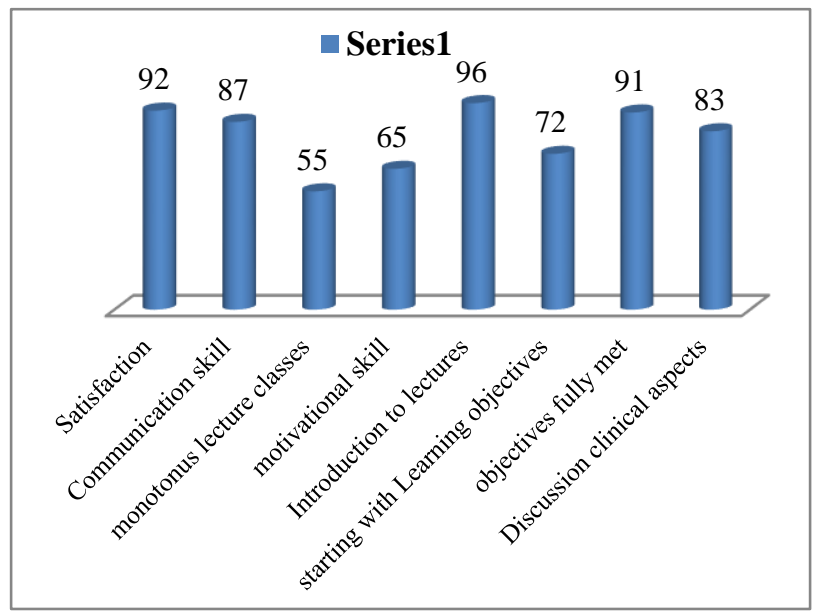

Figure 1: Grading of students perspectives in percentage towards faculty's attributes during lecture classes.

$98 \%$ of students said that faculties teaching was audible clearly and $92 \%$ said that they also clear the doubts then and there (Figure 2).

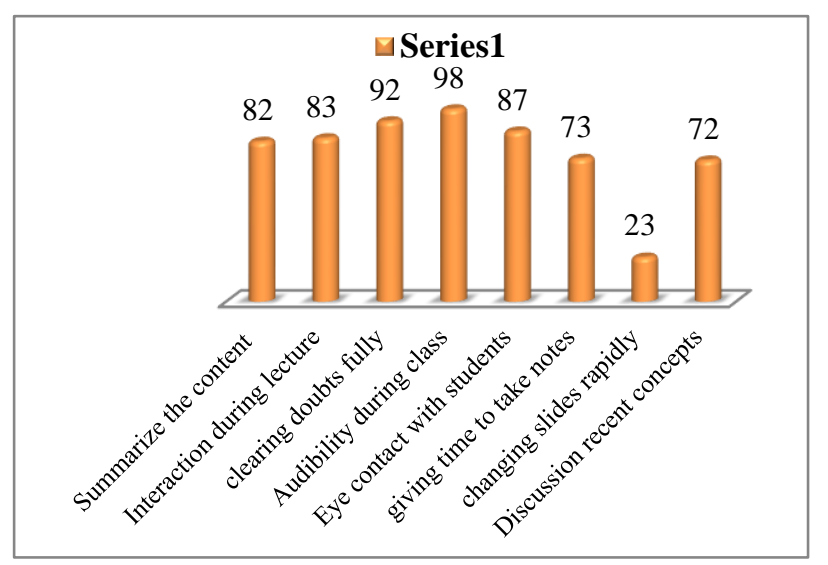

Figure 2: Grading of students attitude in percentage towards lecture classes.

$98 \%$ of students suggest that all faculties should be student friendly, 63\% suggested providing teaching material one week before the class so that they can read the concepts in better way (Figure 3 ). 


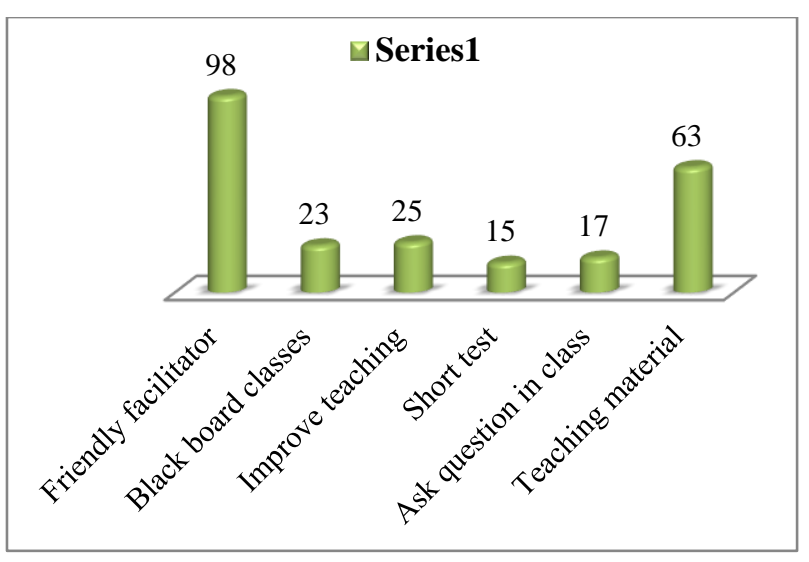

Figure 3: Grading of students' suggestion in percentage towards lecture classes.

In students' aspect $85 \%$ told that they ask doubts in the class, $70 \%$ of the students said that they take notes during class (Figure 4).

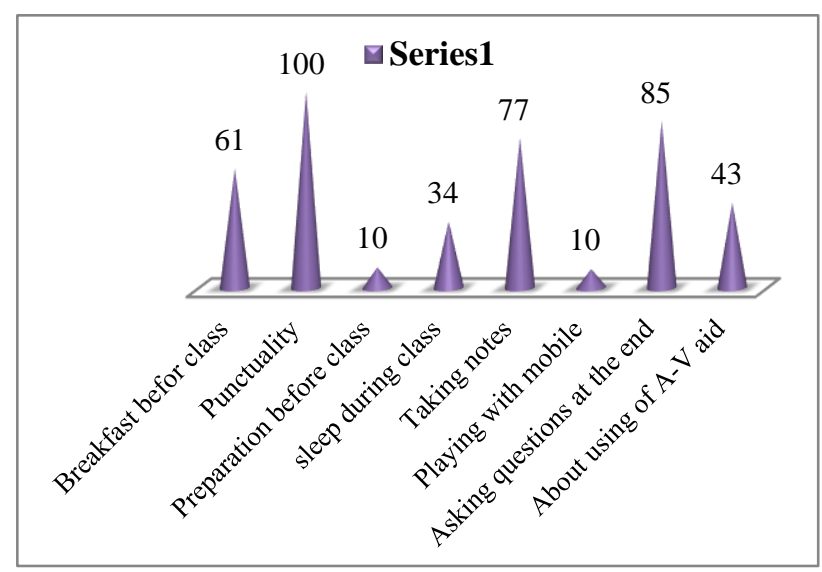

Figure 4: Students feedback in percentage for the given questionnaire.

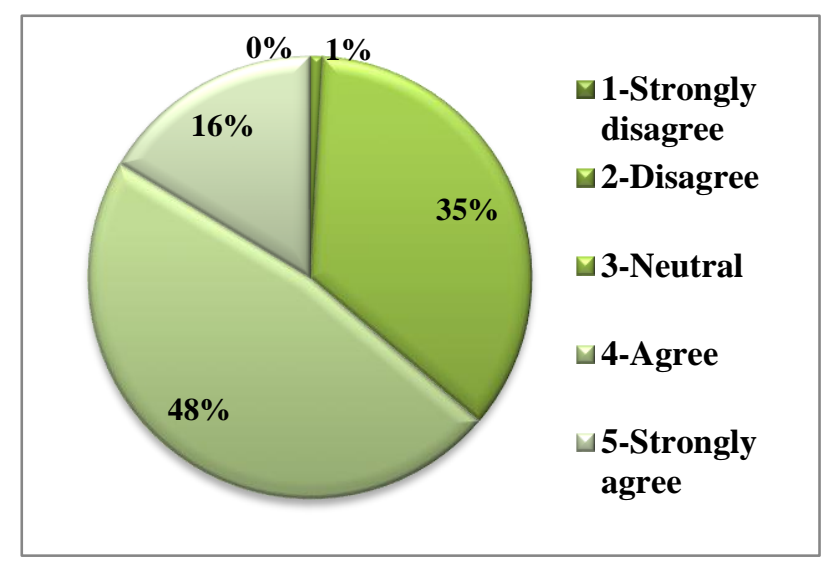

Figure 5: Students attitude towards teaching proficiency in percentage.

Out of 115 students who attended the questionnaire session, $61 \%$ students were having a very good and better attitude towards the faculty talking Pharmacology lecture classes and remaining students have a few lacking areas in the teaching mode which should be analyzed (Figure 5, 6 and 7).

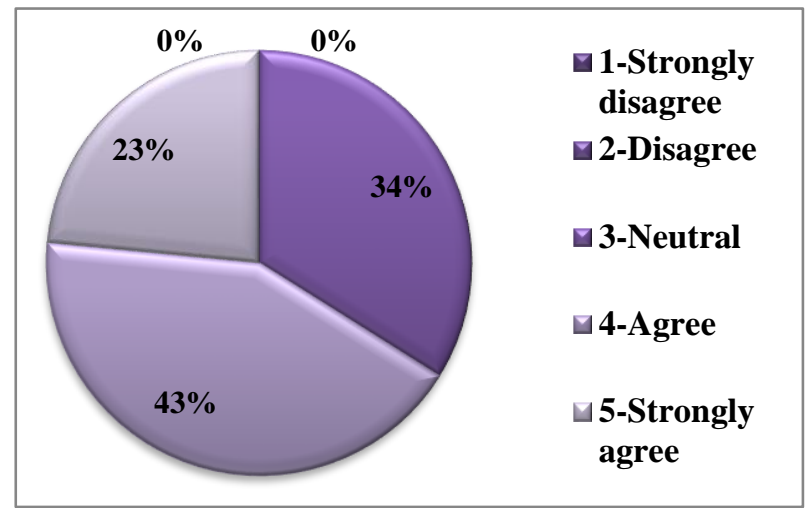

Figure 6: Students attitude towards the teaching content in percentage.

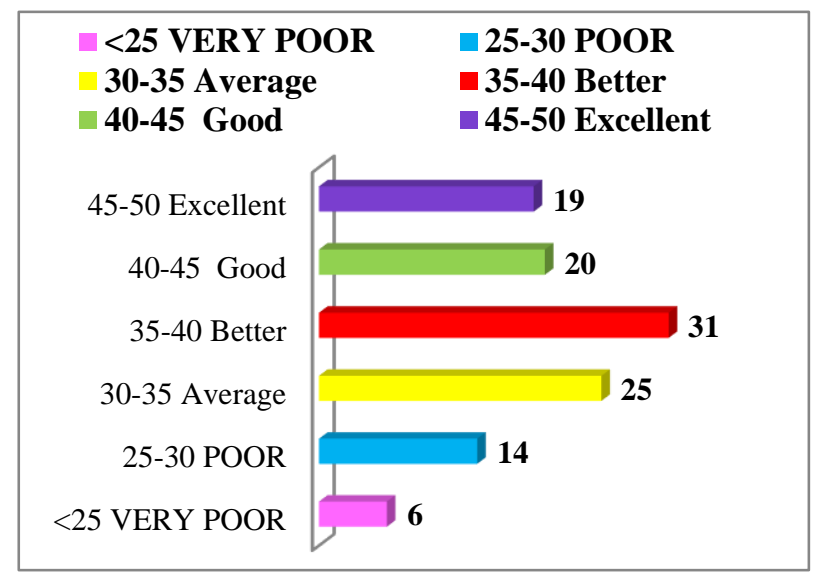

Figure 7: Scoring of Students attitude towards didactic lectures.

\section{DISCUSSION}

Out of 145 second year medical students, only 115 students participated in the research study by filling the questionnaire after giving informed consent. Around $100 \%$ students have told that the teachers were punctual to lecture classes. $96 \%$ of students accepted that the faculty gave introduction, stressed upon learning objectives and reinforced at the end of the class after summarizing. $92 \%$ of students were satisfied with the faculty teaching. This satisfaction is important because it shows that at least half of the student's population tries to understand the concepts. $91 \%$ of students had stated that the objectives of the class were completely met. $65 \%$ was satisfied with the faculty's motivation skills.

$87 \%$ of students felt that the linguistic skills of faculty were good. $83 \%$ of students felt that the faculty gave enough clinical background concerned to the theory topic. These results showed that the faculties were efficient in disseminating the relevant concepts and that 
they could also give real life examples for the clinical cases which would make a good impact on the topic by the students. ${ }^{4}$

$83 \%$ and $92 \%$ of students said that the teaching staffs interacted and cleared doubts regularly during the lecture hours. Approximately $45 \%$ of students agreed that the teaching aids used by faculty were good. $87 \%$ of students told that faculties have good eye contact with them during lectures. $98 \%$ of students said that faculty teaching was clearly audible during the lecture. $73 \%$ of students felt the faculty had given enough time for taking notes. Students who took notes during the lecture regularly were found to be $77 \%$. Earlier studies have also stated that in order to improve the understanding of the students and for their future referencing, enough time to take notes has to be given which will in-turn improve the learning skill of the students. ${ }^{4}$

Regarding pitfalls during teaching was that, $23 \%$ felt that the faculty changed the slides rapidly. $25 \%$ of students felt that the faculty could further improve the way of teaching. $55 \%$ of students felt that lecture classes were monotonus. In the previous studies, they have mentioned that breaking the monotony for every 20 minutes by directing questions towards the students and also by showing some slides unrelated to the theory topic (E.g. Vacation slides) will be helpful and prevent the students from getting bored.,

Merely $10 \%$ of students said that they come prepared for the theory classes. It is good to come prepared for the theory classes because they could understand the entire concepts clearly and also clarify the doubts in the theory class itself. $30 \%$ of students used to sleep occasionally during the class hours. It shows that faculties should take few more steps to make the theory classes much more interesting, as we discussed earlier by giving some reallife examples and by breaking the monotony. ${ }^{4,7-9} 10 \%$ of students stated that they would play with mobiles during the lecture classes. Institutions should make some arrangements to restrict the mobiles at least during the academic hours so that the student's distractions can be reduced. It can also be minimized by modifying the theory class into active and interactive learning sessions which involves both the students and the teacher actively taking part in the teaching learning process.

Now considering the role of small group teaching and problem based learning etc., we can incorporate these methods in between the theory classes to make the topic much more interesting. Studies have also shown better results by use of these methods in teaching. $5,10,11$

Regarding the students' suggestions, $98 \%$ of the students wanted the faculty to be a friendly facilitator, so that they can easily approach the faculty whenever it's needed. Studies have also shown that by incorporating Postgraduates in Under graduates teaching program, it will improve the imparting of knowledge and learning skill in the students. ${ }^{12}$ Merely $23 \%$ of students wanted the class to be taken purely in a black board. Black board teaching is necessary but still it wouldn't be completely sufficient to ensure that all scientific concepts to be effectively delivered through this approach. So we can also use Audio visual aids and hand models to describe the topic. $63 \%$ of students wished to get the teaching material one week before the class. $15 \%$ of students suggested to keep short tests at periodic intervals.

Out of 115 students $70(61 \%)$ students were having a very good and better attitude towards the faculty taking Pharmacology lecture classes. So instead of giving monotonus lecture classes alone, we can also incorporate multiple modes of teaching methods as we have discussed above to improve the knowledge and learning skills in the students.

\section{CONCLUSION}

From the results of the study conducted regarding the attitude of students towards the didactic lectures, it was found that overall students' satisfaction was good. However, faculty could further improve their skills in certain areas like motivating the students, communication skill, usage of needed teaching aids, interactive teaching class which include recent advances and discussion of clinical points. Regarding the suggestions of the students, they expect every faculty to be a friendly facilitator, in addition to periodic short tests to evaluate their understanding of the subject. Thus, continuous monitoring of faculty and student performance by means of assessment is mandatory.

The final expectation from every faculty in a medical college is to bring out a knowledgeable and skilful Indian medical graduate which is an achievable process. Suggestions from the students must be taken in to consideration to implement better teaching methods than before. This can be achieved by the efficient planning of interactive and interesting lecture methods for the usefulness of students as well as the teacher.

\section{ACKNOWLEDGMENTS}

Authors would like to thank the students who participated in the study and the Karpagam Faculty of Medical Sciences and Research, Coimbatore, the institution where the study was conducted.

\section{Funding: No funding sources \\ Conflict of interest: None declared \\ Ethical approval: Not required}

\section{REFERENCES}

1. Sudha J. Graduate training programmes in pharmacology in India. Health Adm. 2006;19(1):8891. 
2. Mohan L, Shankar PR, Kamath A, Manish MS, Eesha BR. Students' attitudes towards the use of audio visual aids during didactic lectures in pharmacology. J Clin Diagn Res. 2010;4(6):3363-8.

3. Tisonova J, Hudec R, Szalayova A. Experience with problem oriented teaching in pharmacology. Bratisl Lek Listy. 2005;106(2):83-7.

4. Richardson D. Don't dump the didactic lecture; fix it. Adv Physiol Educ. 2008;32(1):23-4.

5. Rathnakar UP, Gopalakrishna HN, Pai PG, Ullal SD. Didactic lecture and interactive sessions in small groups: A comparative study among undergraduate students of pharmacology in India. Journal of Diagnostic and Clinical Research. 2010;4(2):2260-4.

6. Uebersax JS. Likert scales: dispelling the confusion. Statistical Methods for Rater Agreement website. 2006. Available from: http://johnuebersax.com/stat/likert.htm.Accessed:July 25, 2015.

7. Michael JA, Modell H. Active Learning in Secondary and College Scienc Classrooms. Mahwah, NJ: Erlbaum; 2003.

8. Myers C, Jones T. Promoting Active Learning:
Strategies for the College Classrom. San Francisco, CA: Jossey-Bass; 1993.

9. Angelo TA, Cross KP. Classroom Assessment Techniques. A Handbook for College Teachers (2nd ed.). San Francisco, CA: Jossey-Bass; 1993.

10. Washington ET, Tysinger JW, Snell LM, Palmer LR. Implementing Problem based Learning in a Family Medicine Clerkship. Fam Med. 1998;30(10):720-6.

11. Goshtasebi A, Zarifi A, Tarami B, Ghorbani A. Small group teaching in epidemiology courses. Journal of Medical Education. 2006;9(1):11-5.

12. Kalra R, Modi J, Vyas R. Involving postgraduate's students in undergraduate small group teaching promotes active learning in both. Int $\mathbf{J}$ Appl Basic Med Res. 2015;5(1):S14-7.

Cite this article as: Umamaheswari A,

Umamageswari MS, Vinotha SAT. Assessment of medical students' attitude towards didactic lectures taken in pharmacology in a private medical college. Int J Basic Clin Pharmacol 2017;6:1451-5. 